\title{
Electricity: Domestic Consumption Versus Export
}

\author{
Gyanendra Lal Pradhan
}

Abstract: Due to its unique geography, Nepal is gifted with very high hydropower potential, far greater than generally
accepted figure of $83,000 \mathrm{MW}$ and $43000 \mathrm{MW}$ of theoretical and techno-financial viability. Our neighbors India,
Pakistan and Bangladesh are suffering from huge power shortages. There is no point in debating whether Nepal's
hydropower should be for domestic consumption or for export because the potential of generating hydropower in Nepal
is far greater than its domestic consumption, even in 2050 . Due to the lack of appropriate policies, however, Nepal
suffers from long hours of load shedding. The government policy to subsidize petroleum products was a big mistake
for, like Bhutan, electricity should have been the cheapest source of energy. Politicians are focusing mostly in export-
oriented projects; whereas, higher importance should have been given to projects for domestic consumption. We
should aim at producing twice the needed internal demand. Nepal is poised to reap huge benefits from hydropower.

Key words: Hydropower, domestic consumption, load shedding, export, Nepal

$\mathrm{N}^{\mathrm{e}}$ epal is naturally gifted to produce hydroelectricity. On the one hand, the terrain that stretches between the tall snow-capped mountains in the north and the plains of the south provide the steep gradient required for hydropower development. On the other hand the perennial streams and rivers emanating from the hills and mountains give rise to tremendous hydropower potential in the country. Nepal is one of the richest countries in terms of hydropower potential. Total Hydropower potential in Nepal stands at around 200,000 MW (against the popularly assumed figure of only $83,000 \mathrm{MW}$ ) and is capable of generating one million GW hour of energy. The potential of projects varies with region. For example, the northern part of the country has high head, the mid-hill region has potential for small and medium sized projects and the southern part has high possibility of generating hydropower through larger projects like Sapta Gandaki (6oo MW) and Pancheswor (6480 MW).

Electricity used in the country enhances overall efficiency of the economy by 10 percent. Therefore, national consumption looks more appropriate than the export. But the potential for electricity geneneration is too big for the country to absorb alone. Our demand of $720 \mathrm{MW}$ is increasing by $10 \%$ every year. With this computation, even in 2050, the country cannot consume more than 20,000 MW. Despite the country's economy significantly booming, national consumption of electricity cannot go beyond 50,000 MW by 2050.

\section{Power export- Why debate?}

Export is necessary as Nepal's generation capacity is much higher than its domestic consumption. In sum, there is a need to increase the generation and internal consumption and also export the surplus. Neighboring countries like Pakistan, India and Bangladesh are potential export markets of electricity from Nepal; but the compulsion to reach these countries via India makes India a more attractive market. Today the load shedding figure in Pakistan is alarming, with a short supply of $6000 \mathrm{MW}$ of electricity. In India the load shedding figure stands at 20,000 $\mathrm{MW}$ and in Bangladesh at 200MW. Being in proximity of these potentially large markets coupled with a big production potential, Nepal's hydropower development can boost the country' overall economic development at an accelerated rate in a decade.

\section{Electricity export: Present situation}

Plans to export electricity to India are not new. Large projects like Arun III (402 MW) and Saptagandaki (225 MW) were planned decades back to meet domestic needs and for exporting surplus power. But precious time and resources have been wasted due to misplaced arguments. Karnali Chisapani (10,800 MW), Pancheswor (6480 mw), Koshi (3500 MW) have now been confined only to political discourse. The possibility of the Nepalese populace benefiting from increased power generation is becoming a difficult dream. In 2005, the independent power producers organized a Power Summit to attract foreign investment in hydropower. Many from India, Norway and the UK participated in the Summit with great interest. Until then, the country was not ready for exporting power. This writer was also invited by the ministers under the leadership of Mr. Subash Nembang to discuss the benefits that power export would bring to the general public. After three hours of brainstorming among the ministers, the participants reached an informal consensus that electricity was an essential commodity for national use and as an export item. This was a great achievement for me and it infused in me a renewed enthusiasm to promote this sector.

In the meantime, the government expedited the process for development of West Seti (750 MW). Unlike in the past, however, the government also invited global competitive bids for Karnali (300 MW), 
Budhi Gandaki (6oo MW) and Arun III (402 MW). The best foreign companies and infrastructure developers came forward. Karnali was offered to GMR India and Arun III to Satluj. The agreement has already been made. Table 1 lists the projects being pursued with the initiative of the private sector for exporting power to India.

These projects are estimated to be completed within

\begin{tabular}{llll}
\hline & Project & Developer & MW Capacity \\
\hline 1. & Upper Karnali & GMR & 300 \\
2. & Arun III & Sutlej & 402 \\
3. & Upper Marsyangdi-2 & GMR & 275 \\
4. & Likhu, Balephi & Bhilwara & $120+50$ \\
5. & Budhi Gandaki & In tendering process & 600 \\
6. & Upper Karnali St-1 & Everest Power & 184 \\
7. & Dudhkoshi 1 & Avantica Group & 194 \\
8. & SR- 3 (West Seti) & Avantica Group & 57 \\
\hline & & Total & $\mathbf{2 1 8 2 ~} \mathbf{M W}$ \\
\hline
\end{tabular}

Table 1. Projects for Power Export

five to seven years and to bring in Rs 400 billion investment into the country. This alone would contribute a whopping Rs120,000 million to the country in the form of local employment and the use of local resources during the construction phase, effectively boosting economic activities on the periphery of project locations. (Since most of the projects would have investments in Indian currency, Nepal will not have to buy Indian currency using dollars, as is now the practice. This would also contribute to increasing the value of the Nepali Rupee in the market.)

\section{Load shedding}

The Nepalese have not learned from past mistakes; thus, we have had severe load shedding in the country for four consecutive years. The first load shedding was of only few hours. With the construction of Kulekhani project, that load shedding problem was mitigated and there surplus power was available. I still remember how Nepal Electricity Authority (NEA) campaigned then urging the people to "use electricity for cooking" to maximize the domestic use of electricity. If Nepal had followed the right direction then, it would, like Bhutan, have been using electricity as the cheapest source of energy, would have helped save forest and vegetation cover and would have helped lay strong foundation for generating maximum electricity to meet domestic demand. But those golden days did not last long. Due to subsidy being given to kerosene and LPG, people preferred petroleum products to electricity as the cheapest sources of energy. The decision of the government to subsidize petroleum products was a big mistake and the practice of limiting electricity to lighting actually undermined many big projects.

The second load shedding was longer, but that problem was managed with the construction of lower Marsyangdi Project.

The third load shedding took a grave turn in the early 2000 when projects like Arun III could not be constructed. The result was that the whole country was engulfed in darkness. There was no electricity in the morning, evening and also at the midnight. The government desperately started to locate investors and finally agreed to construct Khimti and Bhotekoshi projects to address the problem. Around 10 hours of daily load shedding in the country came to an end only in 2003 with the construction of 144 MW Kali Gandaki-A Project. There was even news of electricity worth thousands of crores going waste and unutilized. No one thought of optimally utilizing the wasted energy within the country, however.

\section{Present load shedding}

Even after knowing that load shedding could recur in the future, no planning exercise was done after 2003, as it was assumed that 70 MW Middle Marsyangdi project would be completed on time. But, it is still delayed. Therefore, the fourth load shedding began in 2006. In 2007, the load shedding duration reached to a whopping 48 hours a week. This had serious implications for both business and industry, and for daily life. The 24-hour operations of FM radio stations were worst hit. Load shedding coupled with the severe disruption caused by Terai bandhs further added to the problem of short supply of daily necessities. If there had been sufficient supply of electricity, the population would have consumed it even if it was expensive.

\section{Power export and load shedding}

As mentioned above, big projects of more than 3000 MW have in a very short time moved ahead for power export, but the mobilization of the Nepalese investors to meet the domestic demand has not been encouraging. The export projects are enjoying political and economic benefits. To appease India and to make their own pockets full, the politicians are focusing more on the export projects than on domestic market-oriented projects . Power projects constructed by Nepalese at $\$ 2,000$ per $\mathrm{kW}$ can be constructed for export at $\$ 1,500$ per $\mathrm{kW}$. This is not because of the competency factor of the foreign investors, but because of the cumulative cost advantage associated with larger projects. Upper Karnali is being talked about as a $300 \mathrm{MW}$ project, but it is sure that the Indian investors may construct it for $450 \mathrm{MW}$. Even if the $3,000 \mathrm{MW}$ capacity project is constructed in the 
coming six years, the capacity being computed for the wet season will not be applicable during winter when the actual total production capacity will be only 1,000 MW. This means that if Nepal gets 12.5 percent free energy only then it can address $125 \mathrm{MW}$ of the load shedding problem. This is going to relieve only two hours of the load shedding.

The export projects might contribute to local resource mobilization and help uplift national economy, but they will not significantly help reduce the load shedding problem, and projects to help India solve its load shedding problems while there is persistent load shedding in Nepal are not going to be accepted by Nepalese. Nepal will not gain anything if the revenue generated through export projects is spent on buying back electricity at a higher rate from India. Therefore, while the pace for export projects is being speeded up, there is need for commitment and initiatives to advance projects for Nepali consumption as well so that the internal demand could be met.

\section{Load shedding: till when?}

Analysing the present situation and the basis for power export, it seems that load shedding will never end unless we buy electricity from India with dollars. To solve the power outage problem by buying electricity from India is only a temporary remedy. If we concentrate only on buying from India, in a very short time huge resources will be drained to India. As a result, the NEA would also collapse like the Nepal Oil Corporation is collapsing. Ultimately, we would not only be dependent on India for petroleum products but also for electricity. Various short-term and medium-term solutions plus Nepalese projects for Nepalese consumption are essential to solve the power outage issue. The NEA's ambitious Upper Tamakoshi Project (309 MW) plus 650 MW projects, even if initiated, cannot solve the power problem in the country. We should aim at producing twice the needed internal demand. The private sector should initiate large projects like the 100 MW Kali Gandaki Gorge Project along with small projects of 5-10 MW to address the current problem of load shedding.

If Nepal had followed the right direction early on, it would, like Bhutan, have been using electricity as the cheapest source of energy. This would have helped lay a strong foundation for generating maximum electricity to meet domestic demand and would, at the same time, have helped to enhance forest and vegetation cover.

Gyanendra Lal Pradhan, Hydropower Specialist and Entrepreneur, is an electrical engineer by training. He is currently Patron and Chief Strategist at Hydro Solutions, Director of Butwal Power Company, Chairperson of Nepal Hydro and Electric Limited (NHE), Executive member of IPPAN, Director of Hydro Lab and Director of East Nepal Development Endeavor Pvt. Ltd. (Promoter of Upper Mai Hydropower Project). Mr. Pradhan has received the prestigious Best Entrepreneur Award at the Boss Business Excellence Awards, won the Manager of the Year 2006 Award, and has been conferred with other recognition for his sturdy contributions to the field of hydropower and clean energy.

Corresponding address: gyanendra@hydro-solutions.org info@hydro-solutions.org 